\title{
Microstructural Evolution and Oxidation Behavior of T91/T92 Steel upon Long- Term Steam Test
}

\author{
K. Shin ${ }^{1}$, H.Y. $\mathrm{Ma}^{1}$ and Y.S. He ${ }^{1}$, S.Y. Bae ${ }^{2}$ \\ 1. School of Nano and Advanced Material Engineering, Changwon National University, Changwon \\ 51140, Korea \\ 2. Advanced Materials Group, Korea Electric Power Company, Daejeon 305308, Korea
}

Heat resistant steel is heavily used for boiler system for highly efficient power generation, which is mostly operated in supercritical steam environment $\left(\sim 566^{\circ} \mathrm{C}\right)$. Therefore, the high temperature oxidation mechanism of heat resistant steel is that of high interest for understanding and deterring of the premature failure of the boiler parts [1]. Thus, the detailed characterization, i.e., qualitative analysis and quantification microstructural elements such as formation and thickness of corrosion layers and data collection, pertaining to the oxidation behavior upon the usage of such heat resistant steel is a key for maintenance, lifetime extension, and achievement of efficiency improvement of power generation.

In this study, T91 and T92 steels were steam tested at the supercritical condition, i.e., at $600^{\circ} \mathrm{C}, 650^{\circ} \mathrm{C}$ and $700^{\circ} \mathrm{C}$, for 10000,15000 , and 20,000 h. SEM/EDS, EBSD and TEM were used for microstructural analysis of the oxide layer, i.e., morphology, chemical composition, phase distributions and evolution.

Typical SEM/EBSD analysis of T91 and T92 were shown in Figure 1 and Figure 2. The oxide layer formed on the none-treated surface consisted of an outer layer of iron oxide $\left(\mathrm{Fe}_{2} \mathrm{O}_{3}\right.$ and $\left.\mathrm{Fe}_{3} \mathrm{O}_{4}\right)$ and inner layer of chromium oxide $\left(\mathrm{FeCr}_{2} \mathrm{O}_{4}\right.$ and $\left.\mathrm{Cr}_{2} \mathrm{O}_{3}\right)$ on the specimen. Flaking of the iron oxide scale layer was related to coarsening of $\mathrm{Fe}_{3} \mathrm{O}_{4}$ layer in the specimens. The oxidation sequences of T91/T92 under steam environment are: 1) formation of iron oxide out layer and chromium oxide inner layer, 2) growth of $\mathrm{Fe}_{3} \mathrm{O}_{4}$ in iron oxide layer and spallation of iron oxide layer, 3) growth of iron chromium layer and reformation of iron oxide outer layer. $\mathrm{Cr}$ depletion zones were present below the oxide layer in both specimens, formation of which was attributed to the formation of $\mathrm{Cr}$ rich layer.

$\mathrm{Cr}_{23} \mathrm{C}_{6}$ in T91 and Laves phase in T92 specimen were found after the steam test, which were distributed along grain boundaries. Surface grain coarsening (over $20 \mu \mathrm{m}$ ) occurred below oxide layer in T91 specimen $\left(5.1 \mu \mathrm{m}\right.$ in matrix) (Figure 1b), which was attributed to the dissolution of $\mathrm{Cr}_{23} \mathrm{C}_{6}$ at the surface region. However, no grain coarsening occurred in T92 for the high stabilization and pining effect on grain boundaries by Laves phase.

T92 showed better corrosion resistance than that of the T91. Dissolution of $\mathrm{Cr}_{23} \mathrm{C}_{6}$ and surface grain coarsening led to the decomposition of Cr-rich layer, which reduced the corrosion resistance of T91 specimen. 


\section{References:}

[1] L. Tan, X. Ren and T.R. Allen, Corrosion Science 52 (2010) p.1520.

[2] This work was supported by a National Research Foundation of Korea (NRF) grant funded by the Korea government (MSIP) (No. 2011-0030058). The authors acknowledge the provision of specimens from the Korea Electric Power Research Institute.

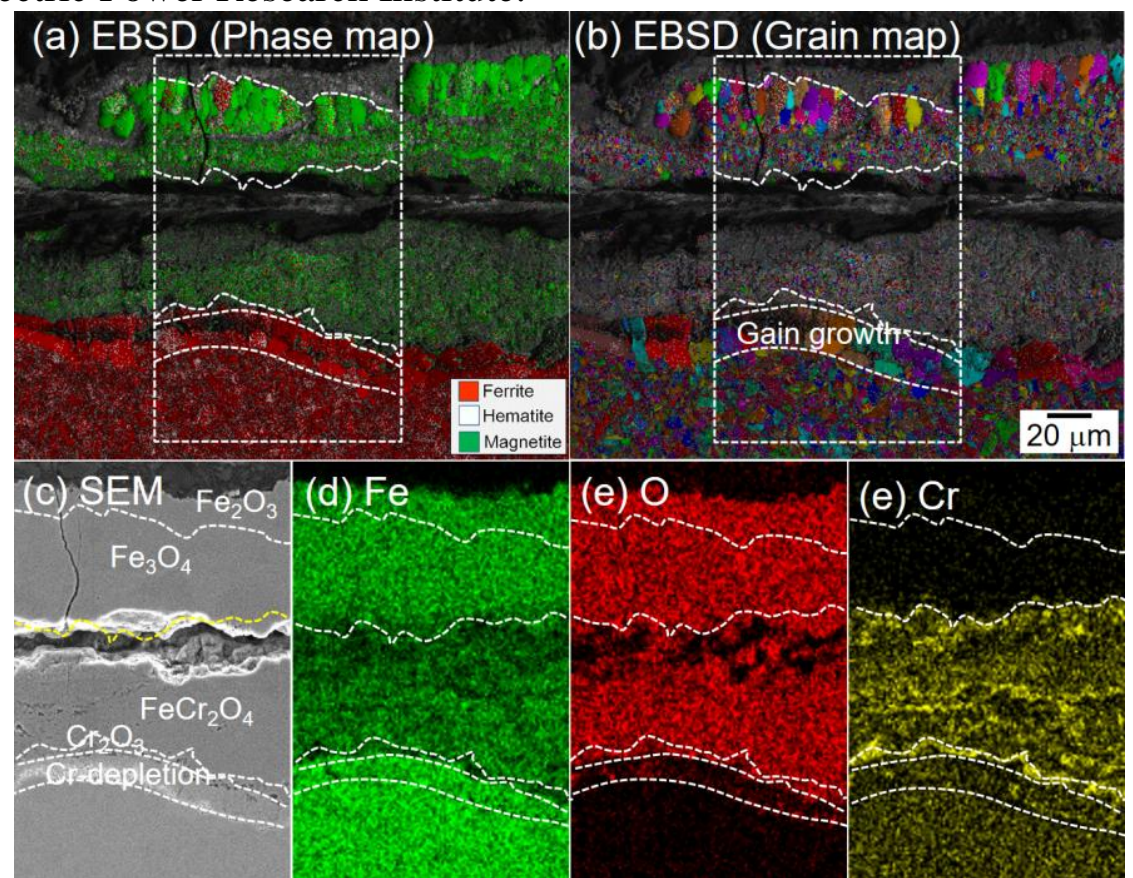

Figure 1. (a) EBSD phase mapping, (b) EBSD grain mapping, (c) SEM, (d) BSE, and (e g) EDS elemental mapping of the steam tested T91 specimen at $650^{\circ} \mathrm{C}$ for $10,000 \mathrm{~h}$.

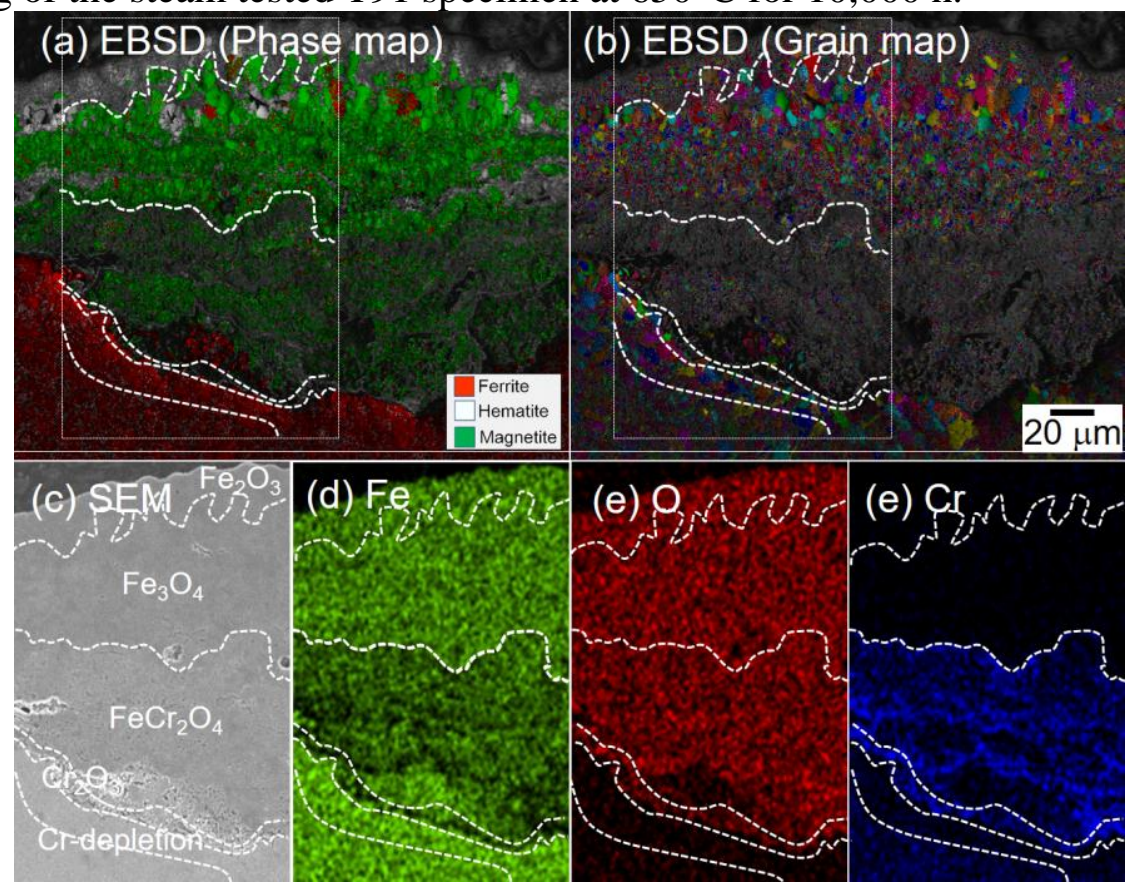

Figure 2. (a) EBSD phase mapping, (b) EBSD grain mapping, (c) SEM, (d) BSE, and (e g) EDS elemental mapping of the steam tested T92 specimen at $650^{\circ} \mathrm{C}$ for $10,000 \mathrm{~h}$. 